Research Paper

\title{
Rhododendron oldhamii leaf extract improves fatty liver syndrome by increasing lipid oxidation and decreasing the lipogenesis pathway in mice
} \author{
Jyh-Horng $\mathrm{Wu}^{1 凶}$ \\ 1. Department of Forestry, National Chung Hsing University, Taichung 402, Taiwan; \\ 2. Department of Forestry and Natural Resources, National Chiayi University, Chiayi 600, Taiwan; \\ 3. Graduate Institute of Metabolism and Obesity Sciences, Taipei Medical University, Taipei 110, Taiwan; \\ 4. Division of General Surgery, Department of Surgery, Changhua Christian Hospital, Changhua 500, Taiwan; \\ 5. Institute of Biomedical Sciences, National Chung Hsing University, Taichung 402, Taiwan. \\ " Equal contributions to this paper.
}

Ya-Ling Liu1 ${ }^{*}$, Lei-Chen Lin ${ }^{2}$, Yu-Tang Tung 3 , Shang-Tse Ho ${ }^{1}$, Yao-Li Chen ${ }^{4}$, Chi-Chen Lin ${ }^{5 凶}$ and

$\square$ Corresponding author: Tel.: +886 4 22840345-136. Fax: +886 4 22851308. E-mail: eric@nchu.edu.tw (J.-H. Wu); Tel.: +886 4 22840896-132. Fax: +886 4 22853469. E-mail: lincc@dragon.nchu.edu.tw (C.-C. Lin).

(C) Ivyspring International Publisher. This is an open access article distributed under the terms of the Creative Commons Attribution (CC BY-NC) license (https://creativecommons.org/licenses/by-nc/4.0/). See http://ivyspring.com/terms for full terms and conditions.

Received: 2017.02.07; Accepted: 2017.05.21; Published: 2017.07.19

\begin{abstract}
Some members of Rhododendron genus are traditionally used as medicinal plants for arthritis, acute and chronic bronchitis, asthma, pain, inflammation, rheumatism, hypertension and metabolic diseases. To the best of our knowledge, there is no report on the protective effects of $R$. oldhamii leaf extract on non-alcoholic fatty liver disease (NAFLD) in vivo and in vitro. In this study, the effects of $R$. oldhamii leaf extract on inhibiting the free fatty acid (FFA)-induced accumulation of fat in HepG2 cells and on improving fatty liver syndrome in mice with high fat diet (HFD)-induced NAFLD were investigated. For the in vitro assay, HepG2 cells were treated with FFAs (oleate/palmitate $=2: 1$ ) with or without treatment with $R$. oldhamii leaf ethyl acetate (EtOAc) fraction to observe lipid accumulation using Nile red and oil red $\mathrm{O}$ stains. For the in vivo assay, $\mathrm{C} 57 \mathrm{BL} / 6$ mice were randomly assigned to three groups $(n$ = 5), including the normal diet group, the HFD group and the HFD+EtOAc group. After 11 weeks, body weight, serum biochemical indices and the mRNA expressions of the liver tissue, as well as the outward appearance, weight and histopathological analysis of liver and adipose tissues were evaluated. Among the fractions derived from $R$. oldhamii leaf, the EtOAc fraction exhibited a strong fat-accumulation inhibitory activity. Following reverse-phase high-performance liquid chromatography (HPLC), four specific phytochemicals, including $(2 R, 3 R)$-astilbin $(A S)$, hyposide $(H Y)$, guaijaverin $(G U)$ and quercitrin $(\mathrm{QU})$, were isolated and identified from the EtOAc fraction of $R$. oldhamii leaf extract. Among them, AS and $\mathrm{HY}$ showed excellent fat-accumulation inhibitory activity. Thus, the EtOAc fraction of $R$. oldhamii leaf and its derived phytochemicals have great potential in preventing FFA-induced fat accumulation. In addition, the EtOAc fraction of $R$. oldhamii leaf significantly improved fatty liver syndrome and reduced total cholesterol (TC) and triglyceride (TG) in HFD-induced NAFLD mice at a dosage of $200 \mathrm{mg} / \mathrm{kg} \mathrm{BW}$. These results demonstrated that the methanolic extracts from $R$. oldhamii leaf have excellent inhibitory activities against fat accumulation and anti-NAFLD activities and thus have great potential as a natural health product.
\end{abstract}

Key words: Rhododendron oldhamii, free fatty acid (FFA), fat accumulation, high fat diet (HFD), non-alcoholic fatty liver disease (NAFLD)

\section{Introduction}

In 2014, an estimated 600 million adults were obesity according to the World Health Organization.
Obesity increases the risk of a number of health problems, including coronary disease, particular 
types of carcinoma, respiratory system complications and osteoarthritis of small and large joints [1]. Genetic, physiological and psychological factors, as well as dietary habits, physical activity, lifestyle and social and environmental factors are responsible for the significant increase in the prevalence of obesity and its consequences [1-4]. Obesity is a condition when fat accumulation is excessive to the extent that it produces adverse health consequences [1]. In the first stage of the two-hit hypothesis, fat accumulation in hepatocytes leads to steatosis, which is related to obesity [5]. In addition, non-alcoholic fatty liver disease (NAFLD) has been considered the 2-stage process of the two-hit hypothesis.

The Rhododendron genus is widely distributed throughout most of the world except for Africa and South America [6]. In traditional medicine, some members of the genus Rhododendron have been used to treat diseases, including arthritis, acute and chronic bronchitis, asthma, pain, inflammation, rheumatism, hypertension and metabolic diseases [7, 8]. A variety of phytochemicals with significant bioactivities, including iridoids [9], diterpenoids [10], triterpenoids [11], chromane derivatives, [12] and flavonoids [13], have been discovered in this genus. $R$. groenlandicum is a popular beverage to treat diabetes symptoms [14]. Ouchfoun et al. [15] showed that $R$. groenlandicum alleviates insulin resistance in a high fat diet (HFD)-induced obesity mice. $R$. arboreum has hypolipidemic activity in a diet-induced hypercholestermic rabbits [16, 17]. In addition, the methanolic extract of $R$. arboretum also showed significant in-vitro antidiabetic activity [18]. Therefore, the present study was undertaken to investigate the
anti-NAFLD effect of $R$. oldhamii leaf extract.

The anti-NAFLD effects of flavonoids in vitro and in vivo models have been reported in several studies [19]. Flavonoids have been shown to help in treating and reducing the risk of obesity [20-22]. In previous studies, plant catechins and anthocyanins reduced the weight of abdominal adipose tissues on diet induced obesity animal models [23]. R. oldhamii is rich in flavonoids, including $(2 R, 3 R)$-epicatechin, $(2 R$, $3 R)$-taxifolin, $(2 R, 3 R)$-astilbin (AS), hyposide ( $\mathrm{HY})$, guaijaverin (GU) and quercitrin (QU) [24]. Therefore, $R$. oldhamii may be a good candidate for further development as a remedy for treating fatty liver syndrome. However, to the best of our knowledge, there is no prior report on the improvement of $R$. oldhamii leaf on fatty liver syndrome in HFD-induced NAFLD mice. Thus, we used both lipid accumulation induced by free fatty acid (FFA; oleate/palmitate = 2:1) in HepG2 cells and HFD-induced NAFLD mouse model to investigate the anti-fatty liver effect of the methanolic extract from $R$. oldhamii leaf.

\section{Methods}

\section{Plant materials}

The leaves of Rhododendron oldhamii Maxim. were collected at the end of April 2011 from the Lion Head Mountain of Taipei county in Taiwan. The species were confirmed by Dr. Lei-Chen Lin of National Chiayi University.

\section{Extraction, fractionation, and isolation}

Extraction, fractionation and isolation were followed by the method of Tung et al. [24]. The leaves were soaked in methanol at ambient temperature for 7<smiles>O=C1c2c(O)cc(O)cc2O[C@H](c2ccc(O)c(O)c2)[C@@H]1O[R7]c1ccccc1</smiles>

$(2 R, 3 R)$-Astilbin (AS)<smiles>[R]Oc1c(-c2ccc(O)c(O)c2)oc2cc(O)cc(O)c2c1=O</smiles>

Hyposide $(\mathbf{H Y}): \mathbf{R}=\mathrm{Gal}$ Guaijaverin $(\mathbf{G U}): \mathrm{R}=\mathrm{Ara}$ Quercitrin (QU): $\mathbf{R}=$ Rham

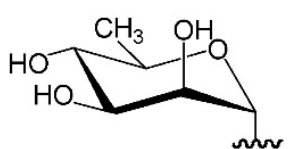

Rham $=\alpha$-L-Rhamnopyranosyl

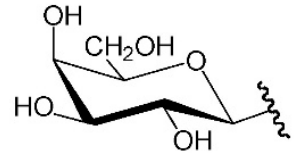

$\mathrm{Gal}=\beta$-D-Galactopyranosyl

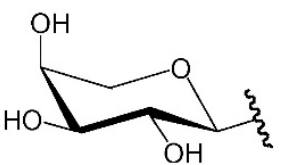

Ara $=\beta$-L-Arabinopyranosyl

Figure 1. Chemical structures of four major phytocompounds isolated from the EtOAc fraction of $R$. oldhamii leaf: (2R, 3R)-astilbin (AS), hyposide (HY), guaijaverin (GU) and quercitrin (QU). 
days to obtain extract. The crude extract was then fractionated with $n$-hexane, ethyl acetate (EtOAc), $n$-butanol $(\mathrm{BuOH})$ and water to yield soluble hexane, EtOAc, $\mathrm{BuOH}$ and water fractions. The 4 major phytochemicals, AS, HY, GU and QU (Figure 1), from the EtOAc fraction were isolated and characterized by HPLC and NMR, respectively.

\section{Cell culture}

The HepG2 cell line purchased from ATCC was cultured in Dulbecco's modified Eagle's medium (DMEM) supplemented with 10\% fetal bovine serum (FBS). The cells were incubated in a $5 \% \mathrm{CO}_{2}$ incubator at $37^{\circ} \mathrm{C}$.

\section{Oil red $O$ staining}

HepG2 cells $\left(2 \times 10^{5}\right.$ cells/well $)$ were seeded into a 6-well plate incubated for $24 \mathrm{~h}$ to allow cell adherence. First, $2 \mathrm{~mL}$ of fresh medium containing test samples was added into the cultures. After $1 \mathrm{~h}$ of incubation at $37^{\circ} \mathrm{C}, \quad 0.25 \mathrm{mM}$ of FFAs (oleate/palmitate, 2:1) was added to the medium and incubated at $37^{\circ} \mathrm{C}$ for $24 \mathrm{~h}$. The cells were rinsed with cold phosphate buffered saline (PBS) and fixed in 1\% paraformaldehyde for $30 \mathrm{~min}$. After the cells were washed with $75 \% \mathrm{EtOH}$, the cells were stained for 20 $\min$ in a $2 \mathrm{mg} / \mathrm{mL}$ oil red $\mathrm{O}$ solution to determine hepatic lipid accumulation. After the stain was removed, the cells were washed with PBS and then counterstained with hematoxylin for $20 \mathrm{~s}$. Representative photomicrographs (400x magnification) were conducted by a camera mounted onto a microscope.

\section{Nile red staining}

Nile red staining was used to specifically stain the intracellular fat. HepG2 cells $\left(2 \times 10^{5}\right.$ cells/well $)$ were seeded into a 6-well plate and incubated for $24 \mathrm{~h}$ to allow cell adherence. First, $1 \mathrm{~mL}$ of fresh medium containing the test samples was added into the cultures. After $1 \mathrm{~h}$ of incubation at $37^{\circ} \mathrm{C}, 1 \mathrm{mM}$ of FFAs (oleate/palmitate, 2:1) was added to the medium and incubated at $37^{\circ} \mathrm{C}$ for $24 \mathrm{~h}$. The cells were collected using $0.05 \%$ Trypsin-EDTA and incubated with Nile red $(1 \mu \mathrm{g} / \mathrm{mL})$ in PBS for $10 \mathrm{~min}$. After PBS washed, the cells were suspended in 1\% formaldehyde and then measured by flow cytometry at a laser excitation wavelength of $488 \mathrm{~nm}$.

\section{Cell viability assay}

To measure the cytotoxicity on the test samples, HepG2 cells $\left(1 \times 10^{4}\right.$ cells/well $)$ were seeded into a 24-well plate and incubated for $24 \mathrm{~h}$ to allow cell adherence. First, $1 \mathrm{~mL}$ of fresh medium containing the test samples was added into the cultures and incubated at $37^{\circ} \mathrm{C}$ for $24 \mathrm{~h}$. Following the removal of the medium, $1 \mathrm{~mL}$ of tetrazolium salt solutions $(1 \mathrm{~mL}$ 3-(4,5-dimethylthiazol-2-yl)-2,5-diphenyl tetrazolium bromide (MTT) in $10 \mathrm{~mL}$ DMEM) was added. After 3 $\mathrm{h}$ of incubation at $37^{\circ} \mathrm{C}$, the medium was removed and $600 \mu \mathrm{L}$ of dimethyl sulfoxide (DMSO) was added to dissolve the formazan crystals. Absorbance was measured at a wavelength of $570 \mathrm{~nm}$ using an enzyme-linked immunosorbent assay (ELISA) reader.

\section{Animals}

The C57BL/ 6 mice ( 6 weeks old) were given a standard laboratory diet and distilled water ad libitum and kept on a $12 \mathrm{~h} \mathrm{light/dark} \mathrm{cycle} \mathrm{at} 24 \pm 2^{\circ} \mathrm{C}$. This study was conducted according to institutional guidelines and approved by the Institutional Animal Care and Use Committee (IACUC) of National Chung Hsing University and conformed to the guidelines of the protocol IACUC-10393 approved by the IACUC ethics committee. After 1 week of acclimatization, 15 mice were randomly divided into two groups: the normal group $(n=5)$ was fed a standard chow diet (ND) and the experimental group $(n=10)$ was fed a HFD. The experimental mice were divided into two groups ( $n=5$ /group): 1 ) HFD receiving no treatment (HFD) and 2) HFD receiving $50 \mathrm{mg} / \mathrm{kg}$ of the EtOAc fraction from $R$. oldhamii leaf. Food intake and body weight were recorded. Following 11 weeks of treatment, mice were sacrificed at 18 weeks of age. At the end of the experiment, each mouse was anesthetized, and the liver and epididymal fat pad tissues were collected.

\section{Biochemical analysis of serum samples}

Mouse blood samples were centrifuged at 1,400 $\mathrm{g}$ at $4^{\circ} \mathrm{C}$ for $15 \mathrm{~min}$, and the levels of serum glucose, glutamate-pyruvate transaminase (GPT), triglyceride (TG) and total cholesterol (TC) were measured using an autoanalyzer (Hitachi 7060, Hitachi, Japan).

\section{Pathological histology}

Liver and epididymal fat pad tissues were fixed in $10 \%$ buffered formaldehyde, and histologically examined with hematoxylin and eosin (H\&E) staining.

\section{RT-PCR}

Total RNA of the liver tissue was extracted using Trizol reagent (Invitrogen) following the protocol specified by the manufacturer. RT-PCR was followed by the method of Tung et al. [25]. The gene expressions of 7 genes (SREBP1, ACC, FAS, CPT1a, $P P A R a$ and $P P A R \gamma$ ) using complementary DNA from liver tissue was analyzed. GAPDH was used as an internal control. 


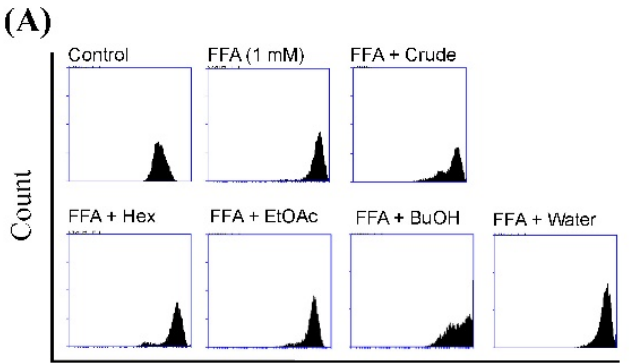

Nile red fluorescence expression

(B)
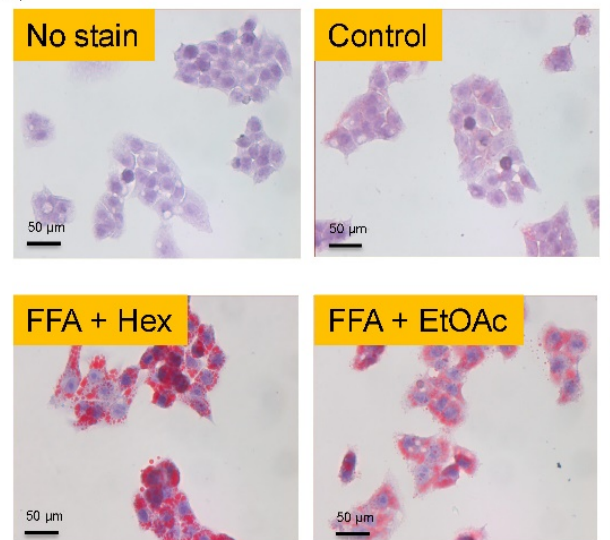

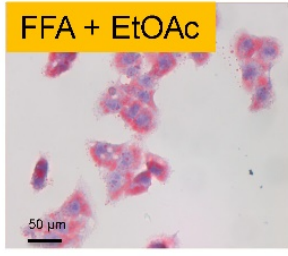

(C)

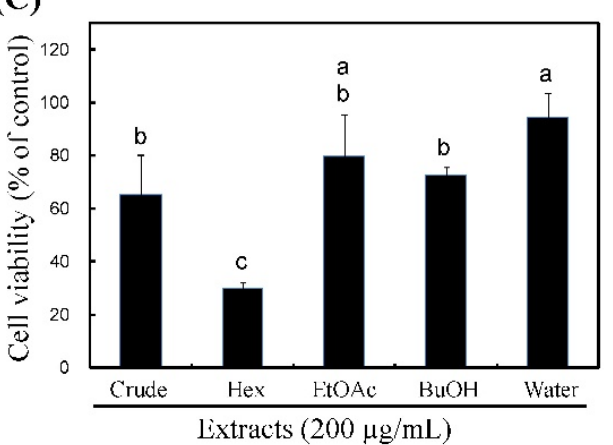

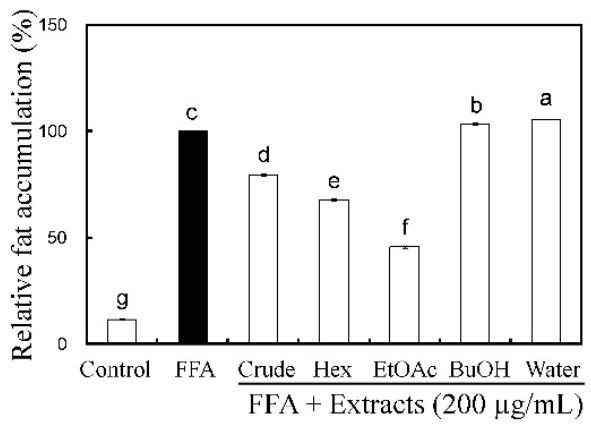
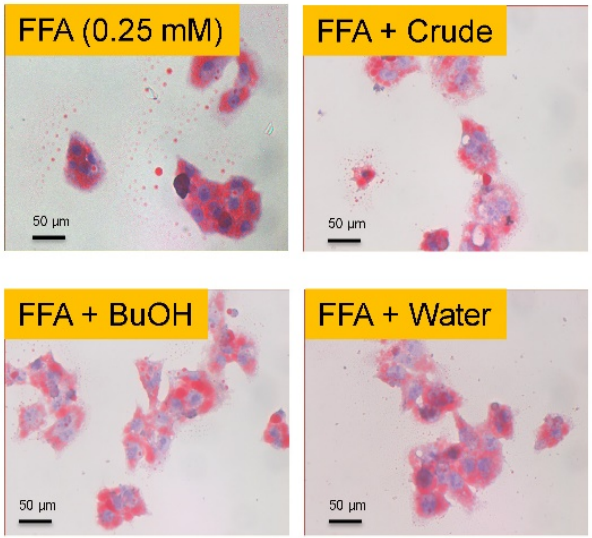

Figure 2. Effects of $R$. oldhamii leaf soluble fractions on intracellular lipid accumulation in HepG2 cells. HepG2 cells were pretreated with $200 \mu \mathrm{gg} / \mathrm{kg}$ of $R$. oldhamii leaf crude and soluble fractions of hexane, EtOAc, BuOH and water in the presence of $0.25 \mathrm{mM}$ of FFAs (oleate/palmitate, 2:1) for $24 \mathrm{~h}$. The cells were stained with Nile red and analyzed by flow cytometry, after which the percentage of lipid accumulation was quantitated (A). Cells were stained with oil red $O$ and analyzed by spectrophotometry (B). Cytotoxicity of $R$. oldhamii leaf soluble fractions in HepG2 cells was measured using the MTT assay (C). The results are presented as the mean \pm SD $(n=3)$. The bars marked by different letters are significantly different at the level of $p<0.05$ according to Scheffe's test.

\section{Statistical analyses}

The data for the in vitro and in vivo assays were expressed as the mean \pm SD $(n=3)$ and the mean \pm SEM $(n=5)$, respectively. Significant differences were calculated by Scheffe's test, and results with $p<0.05$ were considered statistically significant.

\section{Results}

\section{Effects of $R$. oldhamii leaf extract soluble fractions on FFA-induced lipid accumulation in HepG2 cells}

The imbalance between the hepatic uptake of FFAs, TG synthesis and TG excretion leads to fatty liver [26]. Recently, Gomez-Lechon et al. [27] demonstrated that FFA (oleate/PA = 2:1)-induced HepG2 cells mimic benign chronic steatosis. Wu et al. [26] showed that FFA-overloaded HepG2 cells reached maximal intracellular lipid accumulation that was similar with human steatosis. First, we examined whether R. oldhamii leaf crude and soluble fractions of hexane, EtOAc, $\mathrm{BuOH}$ and water were able to reduce lipid accumulation in HepG2 cells induced by FFA using Nile red staining and oil red $\mathrm{O}$ staining. The quantitative data from the Nile red staining displayed that the crude, hexane and EtOAc fractions reduced lipid accumulation by $21 \%(\mathrm{p}<0.05), 32 \%(\mathrm{p}<0.05)$ and $54 \%(\mathrm{p}<0.05)$, respectively (Figure $2 \mathrm{~A})$. Among these, the EtOAc fraction significantly reduced FFA-induced 
lipid accumulation (Figure 2A and 2B). In addition, the MTT assay revealed no significant cytotoxic effects

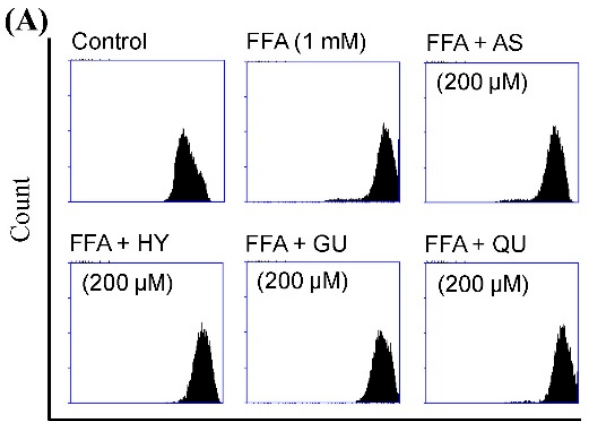

Nile red fluorescence expression

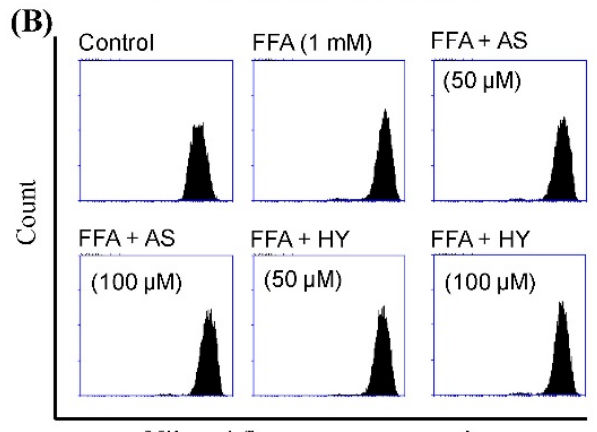

(C)

Nile red fluorescence expression
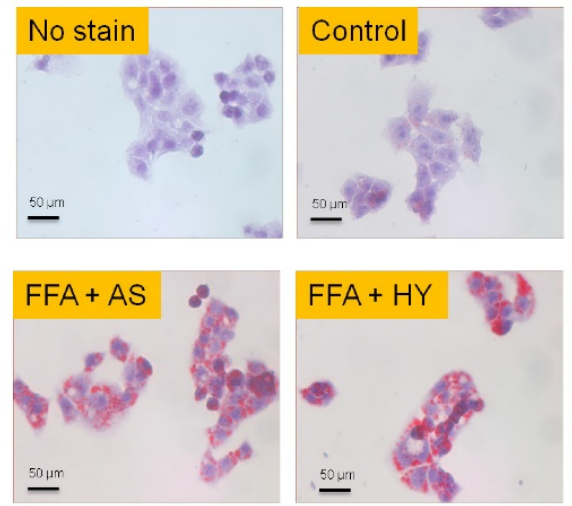

(D)

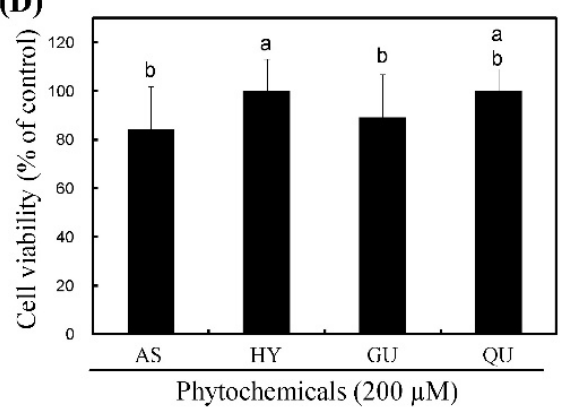

Figure 3. Effects of the phytochemicals from $R$. oldhamii leaf EtOAc fraction on intracellular lipid accumulation in HepG2 cells. HepG2 cells were pretreated with $200 \mu \mathrm{M}$ of AS, HY, GU and QU in the presence of $0.25 \mathrm{mM}$ of FFAs (oleate/palmitate, 2:1) for $24 \mathrm{~h}$. Cells were stained with Nile red by flow cytometry, after which the percentage of lipid accumulation was quantitated (A). HepG2 cells were pretreated with $50 \mu \mathrm{M}$ and $100 \mu \mathrm{M}$ of $\mathrm{AS}$ and $\mathrm{HY}$ in the presence of FFAs for $24 \mathrm{~h}$. Cells were stained with Nile red by flow cytometry, after which the percentage of lipid accumulation was quantitated (B). HepG2 cells were pretreated with $200 \mu M$ of AS, HY, GU and QU in the presence of FFAs for $24 \mathrm{~h}$. Cells were stained with oil red $\mathrm{O}$ by spectrophotometry (C). Cytotoxicity of the phytochemicals in HepG2 cells was measured using the MTT assay. The results are presented as the mean \pm SD $(n=3)$. The bars marked by different letters are significantly different at the level of $p<0.05$ according to Scheffe's test. on cells treated with $200 \mu \mathrm{g} / \mathrm{mL}$ of the EtOAc fraction (Figure 2C).

Bioassay-guided fractionation and quantification of major phytochemicals in $R$. oldhamii leaf EtOAc fraction

R. oldhamii leaf EtOAc fraction showed a stronger inhibitory activity on lipid accumulation than the other fractions, indicating that $R$. oldhamii leaf extract had an inhibitory activity against lipid accumulation, and efficiently enriched in the EtOAc fraction. Thus, the phytochemical characteristics of this fraction were further investigated in this study. The four major phytochemicals of $R$. oldhamii leaf EtOAc fraction were found to be AS, HY, GU and QU (Figure 1), and their contents were determined to be $130.8 \pm 10.9$, $105.5 \pm 8.5,104.1 \pm 4.7$ and 108.6 $\pm 4.0 \mathrm{mg}$ per gram of EtOAc fraction, respectively.

\section{Effects of the}

phytochemicals from $R$.

\section{oldhamii leaf on}

FFA-induced lipid

accumulation in HepG2 cells

The inhibitory effects of the phytochemicals from $R$. oldhamii leaf on lipid accumulation are shown in Figure 3A and 3C. To understand the relationship between the phytochemicals of $R$. oldhamii leaf and its lipid accumulation inhibitory effects in HepG2 cells, 4 constituents, namely AS, HY, GU and QU, were tested. The lipid accumulation inhibitory activities of the four constituents ranke$\mathrm{d}$ in the following order, from highest to lowest: AS > HY > GU $>$ QU. In addition, the MTT assay revealed no significant cytotoxic effects on cells treated with the 4 phytochemicals at the $200 \mu \mathrm{M}$ dosage (Figure 3D). 
Among the 4 phytochemicals tested, AS and HY exhibited the strongest activities. To examine further the inhibition of lipid accumulation in FFA-stimulated HepG2 cells, we selected 2 doses $(50 \mu \mathrm{M}$ and $100 \mu \mathrm{M})$ of AS and HY. Figure 3B shows that HY inhibited FFA-induced lipid accumulation in a concentrationdependent manner.

\section{Effects of R. oldhamii leaf EtOAc fraction on body weight and diet}

The effects of R. oldhamii leaf EtOAc fraction on final body weight and diet intake in HFD-fed mice are shown in Figure $4 \mathrm{~A}$ and $4 \mathrm{~B}$, respectively. The initial body weight for the control and HFD rats were similar. Mice fed the normal diet and HFD continued to increase body weights until the end of the study. After 2 weeks HFD-induced obesity, the body weight was higher for the HFD mice than for the control mice $(\mathrm{p}<0.05)$. After treatment with the EtOAc fraction in the HFD mice, the body weight significantly decreased compared with the HFD group $(\mathrm{p}<0.05)$.
(A)

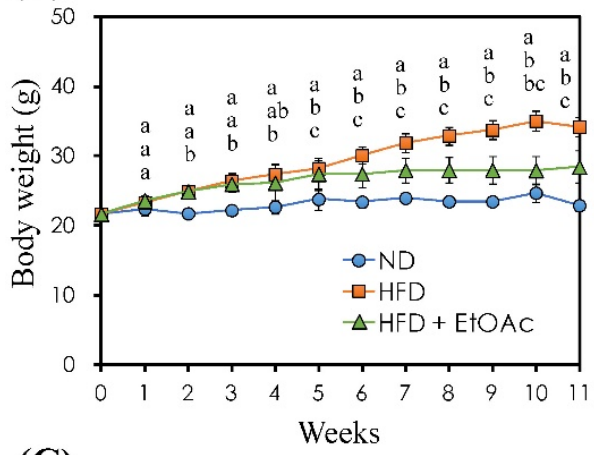

(C)

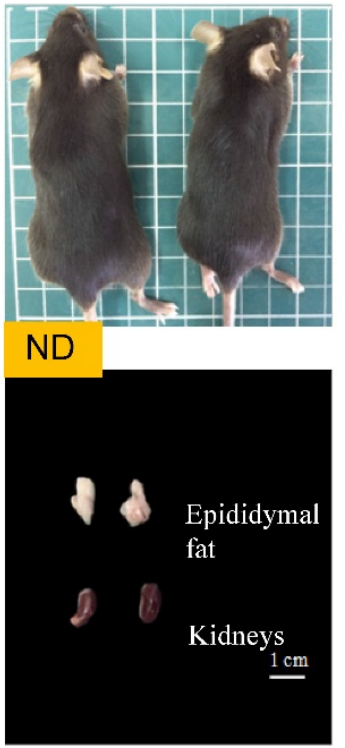
HFD
(B)
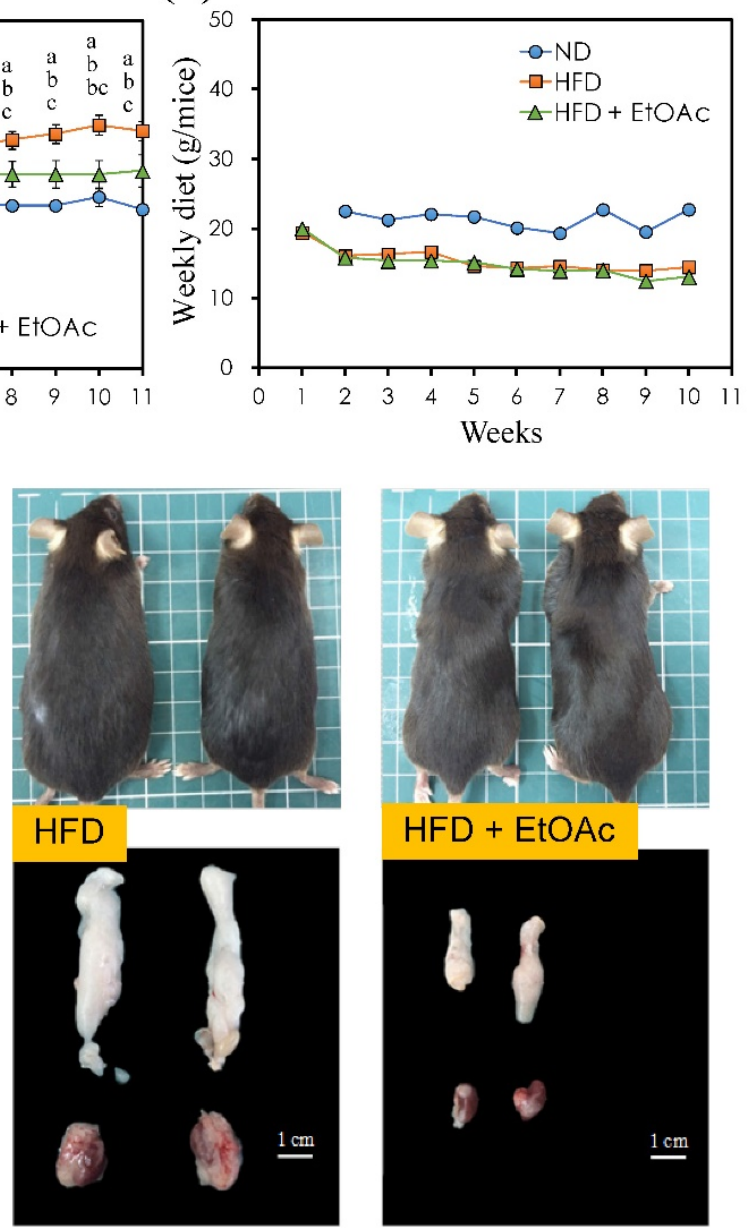

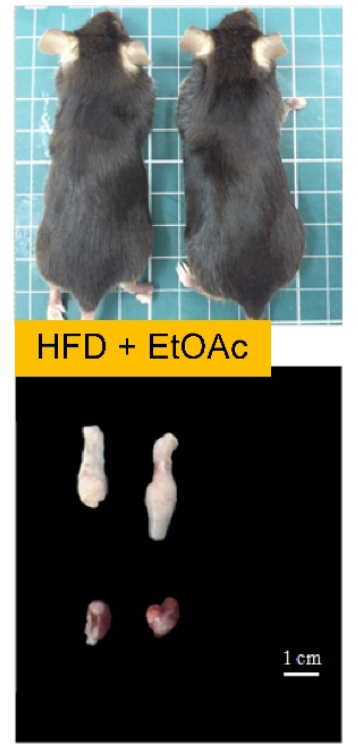

Figure 4. Effects of $R$. oldhamii leaf EtOAc fraction on weekly body weight $(\mathbf{A})$ and diet $(\mathbf{B})$ over the course of 11 weeks in HFD-induced NAFLD mice. The results are presented as the mean \pm SEM $(n=5)$. The markers by different letters are significantly different at the level of $p<0.05$ according to Scheffe's test. Outward appearances, epididymal fats and perirenal fats of C57BL/6 mice at the end of the study (C).
The average final body weight of HFD+EtOAc group decreased by $16.9 \%$ compared with the HFD group. In addition, the HFD group and the HFD+EtOAc group did not show diarrhea during the experiment. HFD groups with or without treatment with $R$. oldhamii leaf EtOAc fraction reduced their daily food intake compared with the vehicle group because HFD had a higher calorie intake than the normal diet.

Table 1. The Epididymal Fat Weights, Liver Weights and Serum Levels of C57BL/6 Mice

\begin{tabular}{llll}
\hline & ND & HFD & HFD+EtOAc \\
\hline $\begin{array}{l}\text { Epididymal fat weight }(\mathrm{g}) \\
\text { Liver weight }(\mathrm{g})\end{array}$ & $0.14 \pm 0.02$ & $1.08 \pm 0.19^{\# \#}$ & $0.48 \pm 0.19^{* *}$ \\
Serum levels & $0.86 \pm 0.09$ & $1.01 \pm 0.08^{\#}$ & $0.81 \pm 0.07^{* *}$ \\
Glucose (mmol/L) & $63 \pm 23$ & $112 \pm 35^{\#}$ & $118 \pm 18$ \\
GPT (U/L) & $133 \pm 100$ & $163 \pm 69$ & $127 \pm 61$ \\
TG (mg/dl) & $81 \pm 5$ & $165 \pm 65^{\#}$ & $116 \pm 17$ \\
TC (mg/dl) & $77 \pm 7$ & $166 \pm 10^{\# \#}$ & $156 \pm 13$ \\
\hline
\end{tabular}

${ }^{\#} \mathrm{p}<0.05 ;{ }^{\#} \mathrm{p}<0.01$ compared with the ND group. ${ }^{* *} \mathrm{p}<0.01$ compared with the HFD group.

\section{Effects of R. oldhamii leaf EtOAc fraction on epididymal fat pad and liver}

The epididymal fat pad (EFP) and liver tissue weights at the end of the study are shown in Table 1 and Figure $4 \mathrm{C}$. The weights of the EFP and liver were higher for HFD alone than for the control mice by $671 \% \quad(p<0.01)$ and $17 \%$ $(\mathrm{p}<0.05)$, respectively. However, the HFD+EtOAc group decreased the weights of both EFP and liver by $56 \%(p<0.05)$ and $20 \% \quad(p<0.01)$ compared with HFD alone. Recent studies showed that high-fat diet induced obesity rats underwent to several enzymatic changes which are related to carbohydrate metabolism in liver and adipose tissues [28, 29]. Thus, this supports the possibility that $R$. oldhamii leaf EtOAc fraction may reduce the formation of adipose tissue through altering several enzymatic reactions. 


\section{(A)}

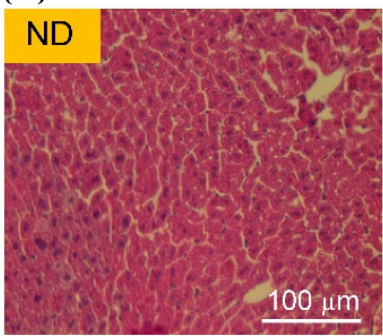

(B)
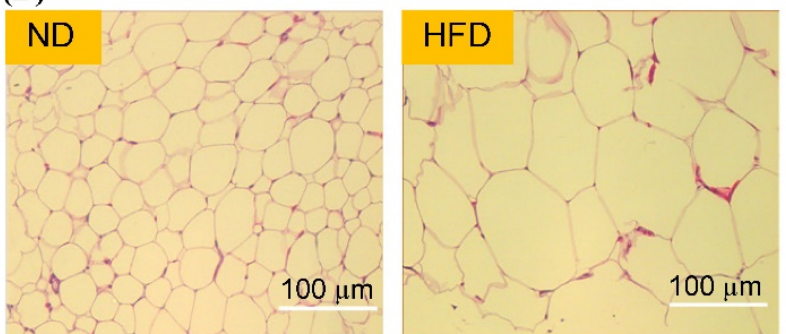

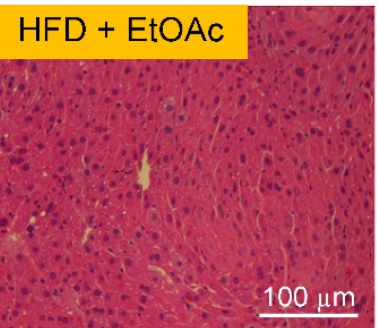

$H F D+E t O A c$

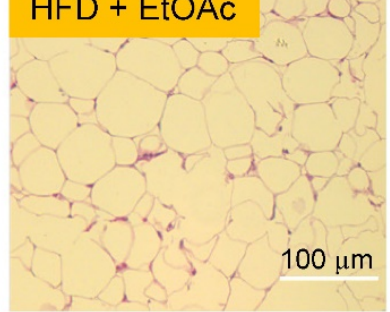

Figure 5. Effects of $R$. oldhamii leaf EtOAc fraction on the hematoxylin and eosin (H\&E) staining of histologically sectioned liver and epididymal fat tissues in HFD-induced NAFLD mice.

\section{Effects of $\boldsymbol{R}$. oldhamii leaf EtOAc fraction on serum biochemical parameters}

The effects of the EtOAc fraction from $R$. oldhamii leaf on glucose, GPT, TG and TC are shown in Table 1. Consumption of a HFD increased the serum levels of glucose, GPT, TG and TC by $77.3 \%(\mathrm{p}<0.05), 23 \%$, $104 \%(p<0.05)$ and $116 \%(p<0.05)$, respectively. After treatment with $R$. oldhamii leaf EtOAc fraction, the HFD+EtOAc group exhibited a slight decrease in the serum levels of GPT (22\%), TG (30\%) and TC (6\%) compared with the HFD group.

\section{Effects of $R$. oldhamii leaf EtOAc fraction on hepatomegaly}

As shown in Figure 5A, histological analysis of the liver tissues revealed abundant foamy cells in the HFD group, and the HFD+EtOAc group showed relatively normal cells compared with the HFD group. $R$. oldhamii leaf EtOAc fraction had inhibitory effects on the formation of foamy cells extending from the hepatic portal vein to the central vein. In addition, adipose tissues of the HFD group showed striking morphological changes (Figure 5B). The EFPs of the HFD+EtOAc group were smaller in size than those of the HFD group, indicating that the reduced total fat mass from treatment with $R$. oldhamii leaf EtOAc fraction may result from decreased TG accumulation rather than a reduced number of adipocytes.
Effects of $R$. oldhamii leaf EtOAc fraction on the expression of genes involved in lipid oxidation and lipogenesis

The mRNA expression patterns of genes encoding enzymes involved in lipogenesis (SREBP1, ACC and $F A S)$ and lipid oxidation (CPT1a, PPARa and PPAR $)$ were assessed using real-time RT-PCR (Figure 6). SREBP1 was reduced by $21 \%(\mathrm{p}<0.05)$, and CPT1a, PPARa and PPAR $r$ were increased by $14 \%$ $(\mathrm{p}<0.05), 30 \%(\mathrm{p}<0.05)$ and $19 \%$ $(p<0.01)$, respectively, in the HFD+EtOAc group compared with the HFD group. Thus, the HFD mice treated with $R$. oldhamii leaf EtOAc fraction exhibited mRNA levels markedly decreased for the lipogenesis gene $(S R E B P)$ and increased for the lipid oxidation genes (CPT1a, PPARa and PPAR $r$ ).
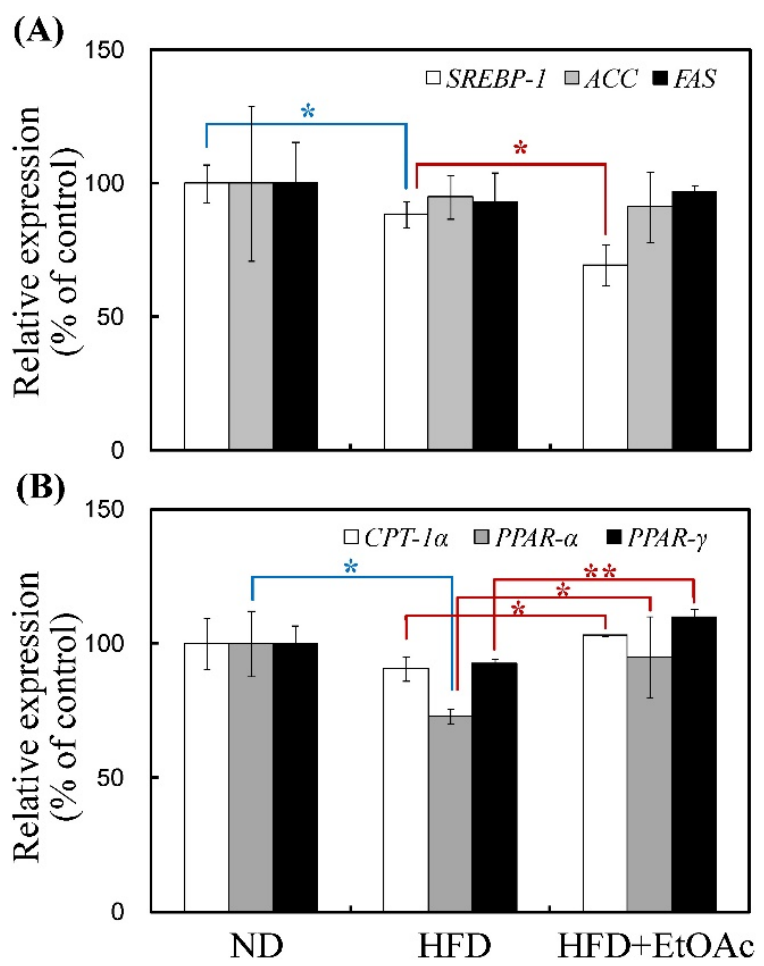

Figure 6. Changes in mRNA expression levels of lipogenesis (SREBPI, ACC and FAS) and lipid oxidation (CPTI $\alpha$, PPAR $\alpha$ and PPAR $\gamma$ ) genes in the ND, HFD and HFD+EtOAc groups. The transcription levels of SREBPI, ACC, FAS, CPTI $\alpha$, $P P A R \alpha$ and PPAR $y$ genes were normalized by an internal GAPDH mRNA control. The data are expressed as the mean \pm SE $(n=5)$. ${ }^{*}<<0.05$ and $* * p<0.01$. 


\section{Discussion}

In recent studies, phytochemicals of plants have shown potential as drug in several metabolic diseases [30]. They have served as template molecules for the development of new drugs [30]. FFA-induced hepatocellular steatosis models have been used to study in several studies on NAFLD pathogenesis and anti-NAFLD drugs [31, 32]. Although primary human hepatocytes represent the most relevant model for the human liver, they are difficult to prepare. Thus, the reproducibility of experimental results is often a large problem [33, 34]. In contrast, the regulation of metabolism of HepG2 cells is different from normal hepatocytes, as HepG2 cells have acquired genetic and epigenetic alterations [35]. In this study, the HepG2 cells with FFA (oleate/palmitate = 2:1)-induced lipid accumulation were used to examine the effects of $R$. oldhamii leaf methanolic extract and its phytochemicals on fatty liver syndrome. Among the fractions derived from $R$. oldhamii leaf, the EtOAc fraction exhibited a strong inhibitory activity against fat accumulation. Following reverse-phase HPLC, four specific phytochemicals were isolated and identified from the EtOAc fraction of $R$. oldhamii leaf extract. In addition, AS and HY showed excellent inhibitory activity against fat accumulation. Thus, $R$. oldhamii leaf EtOAc fraction and its derived phytochemicals have great potential in preventing FFAs from causing fat accumulation. Next, we examined whether $R$. oldhamii leaf EtOAc fraction improved fatty liver syndrome in vivo.

The overconsumption of caloric food contributes to visceral obesity. Therefore, the HFD-induced model represents a valuable tool for investigating and validating new therapeutic avenues for the treatment of obesity and NAFLD [15]. The results of this study showed that $R$. oldhamii leaf EtOAc fraction significantly decreased body weight in HFD-induced NAFLD mice at a dosage of $200 \mathrm{mg} / \mathrm{kg}$ (Figure 4A). This attenuated body weight may be due to the amount decrease of fatty tissue (Table 1) and the adipocyte size (Figure 4C). R. oldhamii leaf EtOAc fraction also significantly reduced the macrovesicular fat quantity in liver tissues of HFD-induced NAFLD mice. In addition, HFD alone elevated TC and TG levels compared with the controls, and R. oldhamii leaf EtOAc fraction significantly reduced the elevated levels of TC and TG in HFD-induced NAFLD mice (Table 1). DeAngelis et al. [36] found that the accumulation of TC in liver parenchymal cells (increase in fat or steatosis), a common liver pathology, is a well-established effect of obesity. Interesting, R. oldhamii leaf EtOAc fraction markedly decreased SREBP1 gene expression and increased CPT1a, PPARa and PPAR $r$ in the livers of
HFD-induced NAFLD mice. These results indicate that $R$. oldhamii leaf EtOAc fraction affected fat deposition by stimulating lipid oxidation and inhibiting the lipogenesis pathway.

\section{Conclusions}

This study demonstrated that consuming 200 $\mathrm{mg} / \mathrm{kg}$ BW of the EtOAc fraction from R. oldhamii leaf for 11 weeks attenuated body weight gain and serum GPT in HFD-induced NAFLD mice. In addition, $R$. oldhamii leaf EtOAc fraction significantly decreased SREBP-1 mRNA; increased CPT1a, PPARa and PPARr mRNA in the liver tissues; and reduced the TG content and TC accumulation in treated HFD-induced NAFLD mice. Therefore, this study demonstrated that the protective effect of $R$. oldhamii leaf in HFD-induced NAFLD mice occurs by an increase in the hepatic lipid oxidation and a decrease in the hepatic lipogenesis pathways.

\section{Acknowledgments}

This work was financially supported by a research grant from the National Chung Hsing University (NCHU-CCH 10311).

\section{Competing Interests}

The authors declare that there is no conflict of interests regarding the publication of this paper.

\section{References}

1. Huang CC, Tseng TL, Huang WC, Chung YH, Chuang HL, Wu JH. Whole-body vibration training effect on physical performance and obesity in mice. International Journal of Medical Sciences. 2014; 11: 1218-1227.

2. Grundy SM. Multifactorial causation of obesity: implications for prevention. American Journal of Clinical Nutrition. 1998; 67: 563S-572S.

3. Hill JO, Peters JC. Environmental contributions to the obesity epidemic. Science. 1998; 280: 1371-1374

4. Wickelgren I. Obesity: how big a problem? Science. 1998; 280: 1364-1367.

5. Salt WB. Nonalcoholic fatty liver disease (NAFLD): a comprehensive review. Journal of insurance medicine. 2004; 36: 27-41.

6. Chung JD, Lin TP, Chen YL, Cheng YP, Hwang SY. Phylogeographic study reveals the origin and evolutionary history of a Rhododendron species complex in Taiwan. Molecular Phylogenetics and Evolution. 2007; 42: 14-24.

7. Popescu R, Kopp B. The genus Rhododendron: an ethnopharmacological and toxicological review. Journal of Ethnopharmacology. 2013; 147: 42-62.

8. Iwata $\mathrm{N}$, Wang $\mathrm{N}$, Yao $\mathrm{X}$, Kitanaka $\mathrm{S}$. Structures and histamine release inhibitory effects of prenylated orcinol derivatives from Rhododendron dauricum. Journal of Natural Products. 2004; 67: 1106-1109.

9. Fan CQ, Zhao WM, Ding BY, Qin GW. Constituents from the leaves of Rhododendron latoucheae. Fitoterapia. 2001; 72: 449-452.

10. Liu CC, Lei C, Zhong Y, Gao LX, Li JY, Yu MH, et al. Novel grayanane diterpenoids from Rhododendron principis. Tetrahedron. 2014; 70: 4317-4322.

11. Choi $\mathrm{YH}$, Zhou W, Oh J, Choe S, Kim DW, Lee $\mathrm{SH}$, et al. Rhododendric acid A, a new ursane-type PTP1B inhibitor from the endangered plant Rhododendron brachycarpum G. Don. Bioorganic \& Medicinal Chemistry Letters. 2012; 22: 6116-6119.

12. Iwata N, Kitanaka S. Tetracyclic chromane derivatives from Rhododendron anthopogonoides. Journal of Natural Products. 2010; 73: 1203-1206.

13. Lin $\mathrm{CY}$, Lin LC, Ho ST, Tung YT, Tseng YH, Wu JH. Antioxidant activities and phytochemicals of leaf extracts from 10 native Rhododendron species in Taiwan. Evidence-Based Complementary and Alternative Medicine. 2014; 2014: 283938.

14. Leduc C, Coonishish J, Haddad P, Cuerrier A. Plants used by the Cree Nation of Eeyou Istchee (Quebec, Canada) for the treatment of diabetes: a novel approach in quantitative ethnobotany. Journal of Ethnopharmacology. 2006; 105: 55-63.

15. Ouchfoun M, Eid HM, Musallam L, Brault A, Li S, Vallerand D, et al. Labrador tea (Rhododendron groenlandicum) attenuates insulin resistance in a 
diet-induced obesity mouse model. European Journal of Nutrition. 2015; 55: 941-954.

16. Murty D, Rajesh E, Raghava D, Raghavan TV, Surulivel MK. Hypolipidemic effect of arborium plus in experimentally induced hypercholestermic rabbits. Yakugaku Zasshi. 2010; 130: 841-846.

17. Verma N, Amresh G, Sahu PK, Rao ChV, Singh AP. Antihyperglycemic and antihyperlipidemic activity of ethyl acetate fraction of Rhododendron arboreum Smith flowers in streptozotocin induced diabetic rats and its role in regulating carbohydrate metabolism. Asian Pacific Journal of Tropical Biomedicine. 2012, 2: 696-701.

18. Bhandary MR, Kawabata J. Antidiabetic activity of Laligurans (Rhododendron arboreum Sm.) flower. Journal of Food Science and Technology. 2008, 4: 61-63.

19. Pisonero-Vaquero S, González-Gallego J, Sánchez-Campos S, García-Mediavilla MV. Flavonoids and related compounds in non-alcoholic fatty liver disease therapy. Current Medicinal Chemistry. 2015, 22: 2991-3012.

20. Narkhede MB. Evaluation of alpha amylase inhibitory potential of four traditional culinary leaves. Asian Journal of Pharmaceutical and Clinical Research. 2012, 5: 75-76.

21. Tsuda T. Regulation of adipocyte functions by anthocyanins: possibility of preventing the metabolic syndrome. Journal of Agricultural and Food Chemistry. 2008, 56: 642-646.

22. Ghosh S, Ahire M, Patil S, Jabgunde A, Bhat Dusane M, Joshi BN, et al. Antidiabetic activity of Gnidia glauca and Dioscorea bulbifera: potent amylase and glucosidase inhibitors. Evidence-Based Complementary and Alternative Medicine. 2012, 2012: 929051.

23. Murase T, Nagasawa A, Suzuki J, Hase T, Tokimitsu I. Beneficial effects of tea catechins on diet induced obesity: stimulation of lipid metabolism in the liver. International Journal of Obesity. 2002, 26: 1459-1464.

24. Tung YT, Lin LC, Liu YL, Ho ST, Lin CY, Chuang HL, et al. Antioxidative phytochemicals from Rhododendron oldhamii Maxim. leaf extracts reduce serum uric acid levels in potassium oxonate-induced hyperuricemic mice. BMC Complementary and Alternative Medicine. 2015, 15: 423.

25. Tung YT, Chen HL, Lai CW, Shen CJ, Lai YW, Chen CM. Curcumin reduces pulmonary tumorigenesis in vascular endothelial growth factor (VEGF)-overexpressing transgenic mice. Molecular Nutrition \& Food Research. 2011, 55: 1036-1043.

26. Wu X, Zhang L, Gurley E, Studer E, Shang J, Wang T, et al. Prevention of free fatty acid-induced hepatic lipotoxicity by $18 \beta$-glycyrrhetinic acid through lysosomal and mitochondrial pathways. Hepatology. 2008, 47: 1905-1915.

27. Gómez-Lechón MJ, Donato MT, Martínez-Romero A, Jiménez N, Castell JV, O'Connor JE. A human hepatocellular in vitro model to investigate steatosis. Chemico-Biological Interactions. 2007, 165: 106-116.

28. Arias N, Macarulla MT, Aguirre L, Milton I, Portillo MP. The combination of resveratrol and quercetin enhances the individual effects of these molecules on triacylglycerol metabolism in white adipose tissue. European Journal of Nutrition. 2016, 55: 341-348.

29. Yeh TS, Chan KH, Hsu MC, Liu JF. Supplementation with soybean peptides, taurine, Pueraria isoflavone, and ginseng saponin complex improves endurance exercise capacity in humans. Journal of Medicinal Food. 2011, 14: 219-225.

30. Kang OH, Kim SB, Seo YS, Joung DK, Mun SH, Choi JG, et al. Curcumin decreases oleic acid-induced lipid accumulation via AMPK phosphorylation in hepatocarcinoma cells. European Review for Medical and Pharmacological Sciences. 2013, 17: 2578-2586.

31. Ricchi M, Odoardi MR, Carulli L, Anzivino C, Ballestri S, Pinetti A, et al. Differential effect of oleic and palmitic acid on lipid accumulation and apoptosis in cultured hepatocytes. Journal of Gastroenterology and Hepatology. 2009, 24: 830-840.

32. Gómez-Lechón MJ, Donato MT, Martínez-Romero A, Jiménez N, Castell JV, O'Connor JE. A human hepatocellular in vitro model to investigate steatosis. Chemico-Biological Interactions. 2007, 165: 106-116.

33. Gómez-Lechón MJ, Donato MT, Castell JV, Jover R. Human hepatocytes as a tool for studying toxicity and drug metabolism. Current Drug Metabolism. 2003, 4: 292-312.

34. Gómez-Lechón MI, Donato MT, Castell JV, Jover R. Human hepatocytes in primary culture: the choice to investigate drug metabolism in man. Current Drug Metabolism. 2004, 5: 443-462.

35. De Gottardi A, Vinciguerra M, Sgroi A, Moukil M, Ravier-Dall'Antonia F, Pazienza V, et al. Microarray analyses and molecular profiling of steatosis induction in immortalized human hepatocytes. Laboratory Investigation. 2007, 87: 792-806.

36. DeAngelis RA, Markiewski MM, Taub R, Lambris JD. A high-fat diet impairs liver regeneration in C57BL/6 mice through overexpression of the NF- $\mathrm{kB}$ inhibitor, ІкBa. Hepatology. 2005, 42: 1148-1157. 